\title{
Dermatophytosis Due to Trichophyton verrucosum and T. mentagrophytes
}

\section{Ali Rezaei-Matehkolaei*}

${ }^{1}$ Health Research Institute, Infectious and Tropical Diseases Research Center, Ahvaz Jundishapur University of Medical Sciences, Ahvaz, Iran. ${ }^{2}$ Department of Medical Mycology, School of Medicine, Ahvaz Jundishapur University of Medical Sciences, Ahvaz, Iran

\section{Letter to the Editor}

Here, I wish to comment that the taxonomy $\mathrm{x}$ of dermatophytes has recently been revolutionized and a new taxonomy was internationally established [1]. Indeed, to update the mycologic data in all aspects of dermatophytosis the new taxa should be considered. Our recent sequencebased investigations in Iran [2,3] and some unpublished data obviously indicate that currently most of the strains morphologically identified as T. verrucosum are, in fact, T. verrucosum var. autotrophicum (Figure 1) which recently regarded to be conspecific with $T$. interdigitale [1]. Additionally, almost all entities phenotypically quoted as T. mentagrophytes are actually the old taxa of T. mentagrophytes var. mentagrophytes or var. granulosum which currently synonymized with $T$. interdigitale species $[1,4]$. Likewise, according to the biological and molecular findings, today it is known that T. mentagrophytes $s p$. is synonymous only with the zoophilic variants and species formerly recognized as T. mentagrophytes var. quinckeanum, T. langeronii and T. sarkisovii. Regarding to the issues under comments, the actual prevalence of $T$. verrucosum, T. mentagrophytes and T. interdigitale species in many recently published studies is questionable. To realize any change in the distribution pattern of dermatophytes, DNA-based procedures and new classification must be considered.

\section{References}

1. Graser Y, Scott J, Summerbell R (2008) The new species concept in dermatophytes-a polyphasic approach. Mycopathologia 166: 239-256.

2. Rezaei-Matehkolaei A, Makimura K, Hoog S, Shidfar MR, Zaini F, et al. (2013) Molecular epidemiology of dermatophytosis in Tehran, Iran, a clinical and microbial survey. Med Mycol 51: 203-207.

3. Abastabar M, Rezaei-Matehkolaei A, Shidfar MR, Kordbacheh P, Mohammad $R$, et al. (2013) A Molecular Epidemiological Survey of Clinically Important Dermatophytes in Iran Based on Specific RFLP Profiles of Beta-tubulin Gene. Iran J Public Health 42: 1049-1057.

4. Nenoff P, Herrmann J, Gräser Y (2007) Trichophyton mentagrophytes sive interdigitale? A dermatophyte in the course of time. J Dtsch Dermatol Ges 5: 198-202

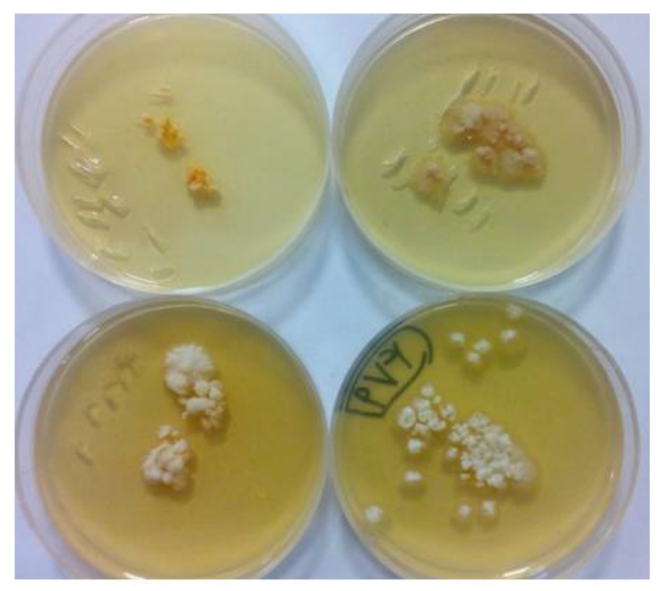

Figure 1: The colony appearance of four dermatophyte strains that morphologically were reported as Trichophyton verrucosum but sequencing specified them as $T$. interdigitale

*Corresponding author: Ali Rezaei-Matehkolaei, Department of Medical Mycology, School of Medicine, Ahvaz Jundishapur University of Medical Sciences, Ahvaz, IR, Iran, Tel: +98 611 3330074; E-mail: a.r.matehkolaie@gmail.com

Received: September 30, 2015; Accepted: November 23, 2015; Published: November 26, 2015

Citation: Rezaei-Matehkolaei A (2015) Dermatophytosis Due to Trichophyton verrucosum and T. mentagrophytes. Dermatol Case Rep 1:101.

Copyright: (c) 2015 Rezaei-Matehkolaei A. This is an open-access article distributed under the terms of the Creative Commons Attribution License, which permits unrestricted use, distribution, and reproduction in any medium, provided the original author and source are credited. 